\title{
Spatial Analysis of Stomach Cancer Incidence in Iran
}

\author{
Reza Pakzad $^{1}$, Yousef Khani ${ }^{2}$, Iraj Pakzad ${ }^{3,4}$, Zohre Momenimovahed $^{5}$,Abdollah \\ Mohammadian-Hashejani ${ }^{6}$, Hamid Salehiniya ${ }^{1,7 *}$, Farhad Towhidi ${ }^{8}$, Behnam \\ Reza Makhsosi ${ }^{8}$
}

\begin{abstract}
Stomach cancer, the fourth most common cancer and the second leading cause of cancer-related death through the world, is very common in parts of Iran. Geographic variation in the incidence of stomach cancer is due to many different factors. The aim of this study was to assess the geographical and spatial distribution of stomach cancer in Iran using data from the cancer registry program in Iran for the year 2009. The reported incidences of stomach cancer for different provinces were standardized to the world population structure. ArcGIS software was used to analyse the data. Hot spots and high risk areas were determined using spatial analysis (Getis-Ord Gi). Hot and cold spots were determined as more than or less than 2 standard deviations from the national average, respectively. A significance level of 0.10 was used for statistical judgment. In 2009, a total of 6,886 cases of stomach cancers were reported of which 4,891 were in men and 1,995 in women (standardized incidence rates of 19.2 and 10.0, respectively, per 100,000 population). The results showed that stomach cancer was concentrated mainly in northwest of the country in both men and women. In women, northwest provinces such as Ardebil, East Azerbaijan, West Azerbaijan, Gilan, and Qazvin were identified as hot spots $(\mathrm{p}<0.1)$. In men, all northwest provinces, Ardabil, East Azerbaijan, Gilan, Qazvin, Zanjan and Kurdistan, the incidences were higher than the national average and these were identified as hot spots $(\mathrm{P}<0.01)$. As stomach cancer is clustered in the northwest of the country, further epidemiological studies are needed to identify factors contributing to this concentration.
\end{abstract}

Keywords: Spatial analysis - incidence - epidemiology - stomach cancer - geographical variation - Iran

Asian Pac J Cancer Prev, 17, Cancer Control in Western Asia Special Issue, 27-32

\section{Introduction}

Cancer is one of the most common diseases around the world so much that it is recognized as the first three causes of death. The statistics show that in 2012, around 14.1 million of new cancers were reported in the world among which 8.2 million led to death. However, it is predicted that in 2030, the new cases of cancer will reach to 21.7 million and death due to cancer will reach to 13 million people which reflects the increasing burden of the disease in the future (Pakzad et al., 2014; Pakzad et al., 2015).

Stomach cancer is the fourth most common cancer and the second leading cause of cancer death in the world. It is responsible for about $10.4 \%$ of all deaths in the world (Almasi et al., 2015). The World Health Organization estimates that each year 930,000 new cases of stomach cancer occur in the world and about 700,000 cases of them result in death (Malekzadeh et al., 2009). Studies in developed countries indicate that the incidence of stomach cancer has decreased, for example, from 1984 to 2013 in Canada the incidence rate reached from 9.5 to18.4 per hundred thousand people (Almasi et al., 2015).

Studies have shown that over the past 30 years, incidence of stomach cancer in Iran, unlike in North American, European countries, and Japan has increased (Sadjadi et al., 2003; Rahimi and Heidari, 2012). And somehow it is still the primary cause of cancer death in Iran. However, this increase was seen in all regions of the country (Hasanzadeh et al., 2013) but in north and northwest of the country, it has been so severe that Northwest provinces in the country have the highest incidence of cancer (Malekzadeh et al., 2009). Comparing gastric cardia cancer in Ardabil with other regions of the world shows that the incidence of cardiac cancer in Ardabil has the highest rate in comparison with other parts of the world including North America, Western Europe, Japan

${ }^{1}$ Department of Epidemiology and Biostatistics, School of Public Health, Tehran University of Medical Sciences, ${ }^{7}$ Minimally Invasive Surgery Research Center, Iran University of Medical Sciences, Tehran, ${ }^{2}$ Alborz University of Medical Sciences, Karaj, ${ }^{3}$ Department of Microbiology, Medical School, ${ }^{4}$ Clinical Microbiology Research Center Ilam University of Medical Sciences, Ilam, ${ }^{5}$ Qom University of Medical Sciences, Qom , ${ }^{6}$ Epidemiologist, Department of Social Medicine, School of Medicine, Rafsanjan University of Medical Sciences, Rafsanjan, ${ }^{8}$ Imam Reza Hospital, Kermanshah University of Medical Sciences, Kermanshah, Iran. *For correspondence: alesaleh70@yahoo.com 
and Korea (Babaei et al., 2005).

Studies have shown significant differences in the incidence of stomach cancer. it has a high incidence in the North West of the country. The difference in the incidence of the disease in different regions may be due to genetic differences and diet, including high salt intake, low intake of fruits and vegetables, and other substances which contain antioxidants (Forman and Burley, 2006; Hasanzadeh et al., 2013). However, the role of environmental factors in cancer has been shown in various studies. studies showed that Pylori infection, smoking, and exposure to industrial materials such as nitrogen oxides, $\mathrm{N}$-nitro compounds, and ionizing radiation are among the important factors of

stomach cancer (Cocco et al., 1994; Forman and Burley, 2006; Hartgrink et al., 2009; Malekzadeh et al., 2009; Radmard, 2010; Hasanzadeh et al., 2013). Studies also have shown a higher incidence of stomach cancer in certain occupational groups, including miners and quarrymen, farmers, fishermen, masonry and concrete workers, machine operators, nurses, food industry workers, cooks, launderers, and dry cleaners (Swanson and Burns, 1995; Kang et al., 1997; Simpson et al., 1999; Aragonés et al., 2002).

Reviewing the geographical distribution of stomach cancer can lead to better understanding of its incidence rate and impact of environmental factors. One of the tools that can assess the distribution of the disease, determine high risk areas and the impact of environmental factors is Geographical information system. There are several studies on usage of this system in the same disease (Bédard et al., 2003; Poulstrup and Hansen, 2004; Çetin et al., 2005; Yomralioglu et al., 2009). Given attention to the point that the knowledge of locational characteristics of the disease incidence can help in prioritizing and giving suitable healthcare and also, due to the absence of similar studies which analyze stomach cancer in Iran, we decided to investigate the spatial distribution pattern of stomach cancer in Iran

\section{Material and Methods}

\section{The study area}

Iran is a country in the Middle-East with the area of 1,648,195 square-kilometers, and is the 18th largest country in the world and has a population of over 75 million (2011) (Rontoyannis et al., 1998). Iran has a variety of environmental conditions in terms of length and breadth of geography, topographic diversity, and a range of altitude up to 5,671 meters above sea level. The Iranian climate varies from arid to subtropical. Iran is bordered by Armenia, Turkmenistan, and Azerbaijan to the north, (as well as by Russia and Kazakhstan via a water border in the Caspian Sea); Afghanistan and Pakistan to the East; the Persian Gulf and Gulf of Oman to the south; Iraq to the east; and Turkey to the northwest (Mostafavi et al., 2013). Iran is currently divided into 31 provinces.

\section{Study design and data collection}

The data was collected from Cancer Registry Center report of health deputy which is based on
Table 1. Standardized Incidence Rate of Stomach Cancer in Iranian Provinces Based on Sex

\begin{tabular}{|c|c|c|}
\hline Provinces & Female & Male \\
\hline Ardebil & 11.6 & 28.9 \\
\hline Esfahan & 7.4 & 12.8 \\
\hline Ilam & 4.8 & 9.1 \\
\hline East- Azarbaijan & 11.5 & 24.8 \\
\hline West-Azerbaijan & 10.9 & 20.3 \\
\hline Bushehr & 1.5 & 5.1 \\
\hline Tehran & 8.6 & 14.8 \\
\hline Chaharmahal-e Bakhtiari & 4.5 & 12.7 \\
\hline South Khorasan & 8.9 & 23.7 \\
\hline Khorasan-e Razavi & 5.0 & 12.6 \\
\hline North Khorasan & 2.6 & 11.6 \\
\hline Khuzestan & 7.6 & 11.3 \\
\hline Zanjan & 6.3 & 21.1 \\
\hline Semnan & 13.7 & 12.8 \\
\hline Sistan and Baluchestan & 1.8 & 4.5 \\
\hline Fars & 4.3 & 10.6 \\
\hline Qazvin & 5.7 & 16.6 \\
\hline Qom & 4.9 & 7.2 \\
\hline Kurdistan & 10.3 & 23.4 \\
\hline Kerman & 6.8 & 11.9 \\
\hline Kermanshah & 8.3 & 10.9 \\
\hline Kohgiluyeh va Boier ahmad & 8.5 & 21.6 \\
\hline Golestan & 6.1 & 18.8 \\
\hline Gilan & 9.7 & 24.1 \\
\hline Lurestan & 7.4 & 16.5 \\
\hline Mazandaran & 10.4 & 25.5 \\
\hline Markazi & 7.6 & 23.0 \\
\hline Hormozgan & 4.1 & 3.5 \\
\hline Hamedan & 7.8 & 18.8 \\
\hline Yazd & 8.8 & 12.8 \\
\hline Total & 10 & 19.1 \\
\hline
\end{tabular}

Iran ministry of health guideline. Data was collected retrospectively reviewing all new stomach cancer patients in cancer registry center report of health deputy for Iran in 2009. Stomach cancer was defined as icd-oc16. Age-standardized rates of cancer incidence were calculated by the direct standardization method, using the world standard population as a reference (Rahimi and Heidari, 2012).

After data collection, Information was entered into Excel datasheets. Using Excel was justified by the faster computational capabilities and the ability to convert and store data in tables which can be linked to geographical maps in ArcGIS software, as well as being an interactive environment for checking numbers simultaneously when entering data.

\section{GIS analysis}

The most recent updated electronic map of Iran 


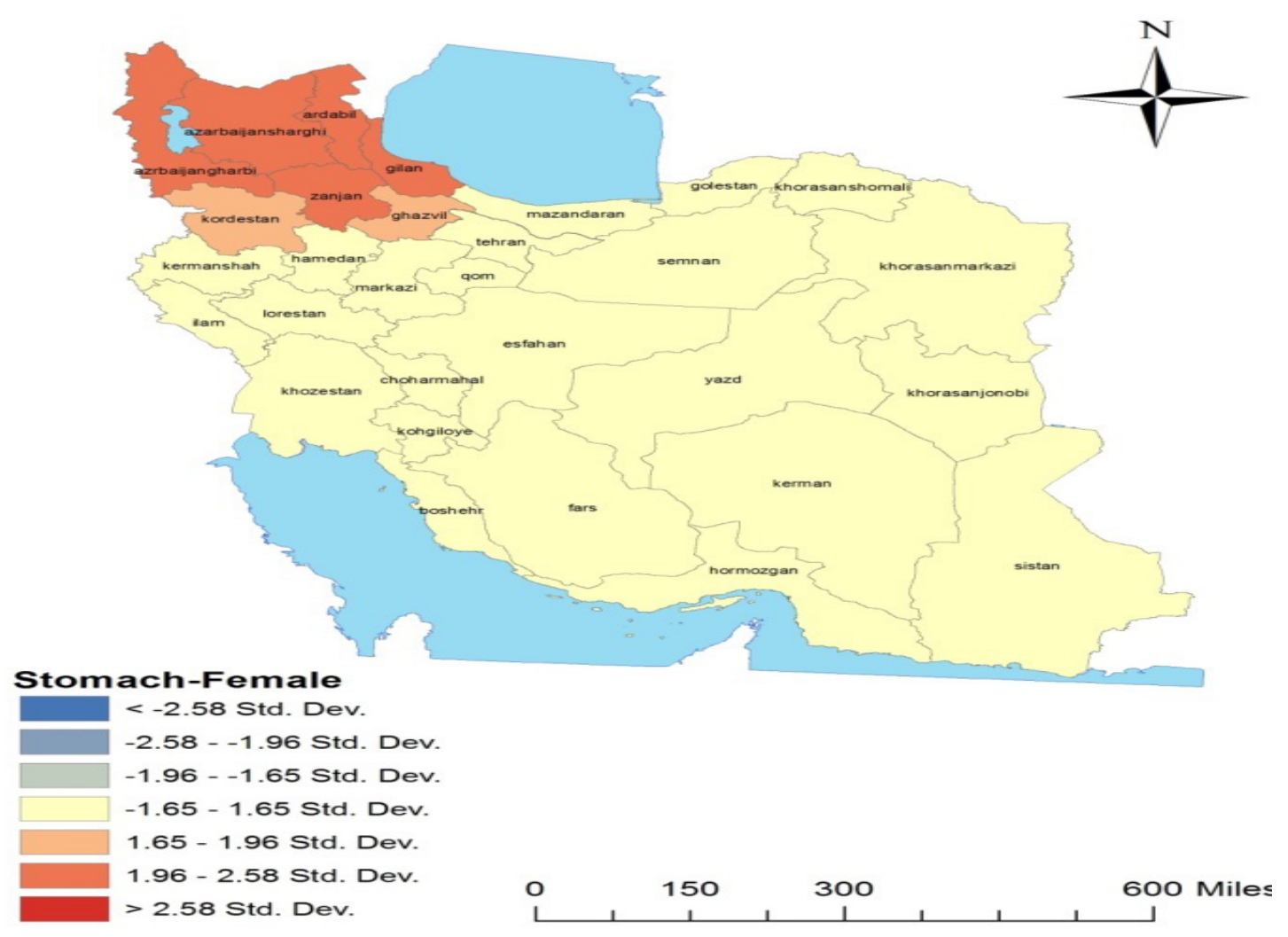

Figure 1. Hot Spots Stomach Cancer in Females (2009)

and its provinces was used. To link data tables to the map, a so-called ID field was created in the Excel tables reporting the incidence of stomach cancer. The code entered corresponded to the code of a province in the map data tables. The tables and map were then linked by a common field.

Identifying disease hotspots was done using Getis-Ord Gi* (Spatial Statistics) (Figure 3). An incidence hotspot was defined as a province which not only has a high incidence of disease itself but also has a neighboring province with a high incidence. In other words, the hotspot analysis shows that provinces with high incidence of disease become a focus of disease if there is high incidence in surrounding provinces as well. To the contrary, it can be said that 'cold spots' are provinces with not only low incidence but also with low-incidence neighbors. Provinces that are higher or lower than the national average which was $1.96 \mathrm{SD}$, considered hot spots or cold spots as they were significant at the level of $0.05 \%$.

\section{Results}

In 2009, a total of 6,886 cases of stomach cancer was reported in which 4,891 were men and 1,995 were women. The annual incidence of stomach cancer in men was 19.2 and in women was 10 per hundred thousand people. The results showed that the highest incidence in women was for Semnan province with the incidence of 13.7 per hundred thousand people and then the Ardabil province with 11.6, East Azerbaijan with 11.5, West Azerbaijan with 10.9, and Mazandaran with 10.4 per hundred thousand with the most incidence. Also the highest incidence of stomach cancer in men was in Ardabil province with 28.9 per hundred thousand people and then the Mazandaran province with the incidence of 25.5, East Azerbaijan with 24.8 and Guilan with 24.1 per hundred thousand people had the Next Level.

The results showed that the distribution of areas with a high incidence of disease was more in provinces of north and northwest of the country. Figures 1 and 2 are for the analysis of hot spots of stomach cancer in women and men. In picture 1 which is related to the incidence of cancer in women, It has been shown that northwest provinces such as Ardebil, East Azerbaijan, West Azerbaijan, Guilan and Qazvin, are among meaningful Hot Spots $(\mathrm{p}<0.05)$. Although the province of Kurdistan and Zanjan had high incidence in comparison with the national average but they aren't considered as Hot Spots.

The second picture is about stomach cancer in men. The hot spots analysis showed that in North West provinces such as Ardebil, East and West Azerbaijan, Guilan, Qazvin, Kurdistan and Zanjan, men had higher incidence than national mean and are recognized as severe Hot $\operatorname{Spots}(\mathrm{p}<0.01)$. Table 1 shows Standardized incidence rate of stomach cancer in Iranian provinces.

\section{Discussion}

Stomach cancer is the second leading cause of cancer death in the world and the first leading cause of cancer death in Iran. Although stomach cancer had a decreasing pattern in Western countries, but the trend is rising in Asian countries such as Iran. That's why it is very important to give attention to the state of incidence and distribution the cancer (Rahimi and Heidari, 2012; Keyghobadi et al., 2014).

Although the incidence of stomach cancer does not 


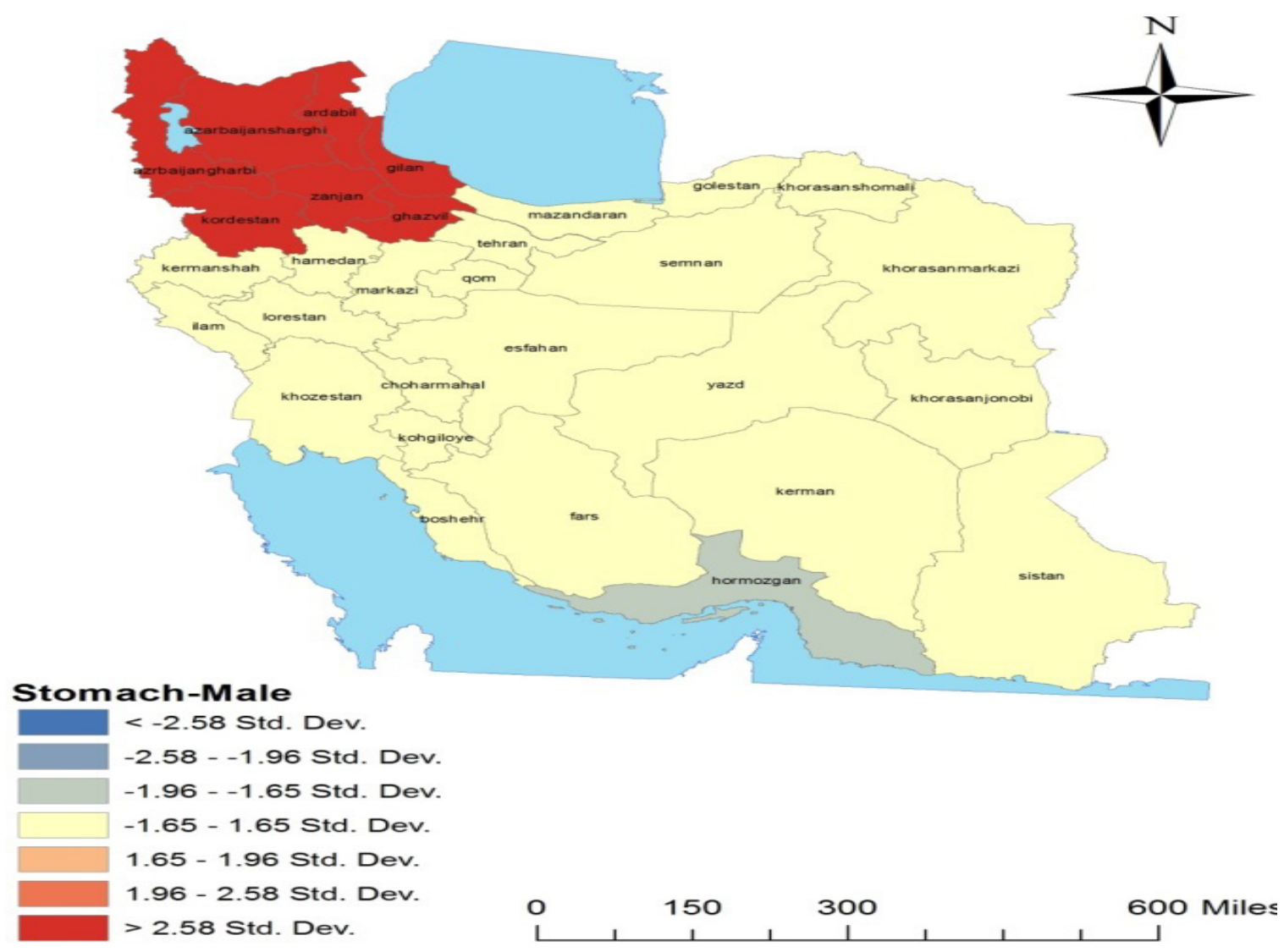

Figure 2. Hot Spots Stomach Cancer in Male (2009)

$$
G_{i}^{*}=\frac{\sum_{j=1}^{n} w_{i, j} x_{j}-\bar{X} \sum_{j=1}^{n} w_{i, j}}{S \sqrt{\frac{\left[n \sum_{j=1}^{n} w_{i, j}^{2}-\left(\sum_{j=1}^{n} w_{i, j}\right)^{2}\right]}{n-1}}}
$$

Figure 3. Getis-Ord Gi* (Spatial Statistics) - Where Xi is the Attribute Value for Feature j, wij is the Spatial Weight Between Feature $i$ and $j, n$ is Equal to the Total Number of Features

follow a specific geographic pattern around the world (Forman and Burley, 2006), however, the distribution of it is different around the world . it has low incidence in Western countries, West Europe, and East Asia and these areas are among the low risk ones (Siegel et al., 2014). However, in Eastern European countries, the Middle East and other Asian countries the incidence is high (Sankaranarayanan et al., 2014) and in some areas, this difference reaches to the tenfold (Parkin et al., 2002).

The significant geographic differences in the incidence of stomach cancer, may be due to differences in the distribution of environmental factors such as dietary factors and Helicobacter pylori infection (Enayatrad and Salehiniya, 2014). Mentis et al (2015) in their review article study showed that the prevalence of $\mathrm{H}$. pylori infection in developed countries is less than developing countries and less developed ones. Also Eusebi et al (2014) in other study showed that the prevalence of $\mathrm{H}$. pylori infection in Asian and African countries is more than Western and developed countries. Also Dorji et al (2014) in their study noted the high prevalence of H. pylori infection in Asian countries. Several studies have been conducted on the prevalence of $\mathrm{H}$. pylori infection in Iran and have shown that the prevalence of Pylori infection in Iranian population is high. in Ardabil province more than $89 \%$ of people over 40 years had infection (Massarrat et al., 1995; Malekzadeh et al., 2009; Sayehmiri et al., 2014).

Our results showed that the northwest provinces of country such as Ardebil had the highest incidence of stomach cancer. A strong spatial clustering of stomach cancer in this area is shown in other studies (Radmard, 2010). In contrast, the southern provinces such as Kerman are among low disease incidence areas (Sadjadi et al., 2007). Although the high incidence of cancer in Ardebil and other northwest provinces of the country could be due to the higher prevalence of risk factors for stomach cancer (Malekzadeh et al., 2009), but also this difference may be due to the higher rates of gastric cardia cancer than non-cardia cancer . It's 26.4 in males and 8.6 per hundred thousand people in women (Derakhshan et al., 2004; Abdi-Rad et al., 2006). Compared with other high-risk areas of stomach cancer, including Japan, non-cardia cancer remains as a major form of stomach cancer (Malekzadeh et al., 2009). Another explanation for the high incidence of stomach cancer in the 
northwest provinces of the country, could be due to a higher prevalence of $\mathrm{H}$. pylori infection. studies have shown that more than $89 \%$ of people over 40 years in Ardebil had infection (Massarrat et al., 1995; Malekzadeh et al., 2009; Sayehmiri et al., 2014).

In addition to Helicobacter pylori infection, other risk factors for stomach cancer including smoking, high consumption of red meat and salt intake and diet with an insufficient level of antioxidants are introduced (Derakhshan et al., 2004; Abdi-Rad et al., 2006; Malekzadeh et al., 2009). Studies have shown that the amount of salt intake in Iranian population is more than the amount recommended by the WHO (Ghadimi et al., 2007). In a study in Ardebil was shown that salt intake is higher in people with stomach cancer (Pourfarzi et al., 2009). Also Gonzalez et al in their study showed that high consumption of red meat can act as a risk factor for stomach cancer (González et al., 2006). this finding is confirmed in studies conducted in areas with a high incidence (Pourfarzi et al., 2009). Other studies have demonstrated the relationship between consumption of hot tea and gastric cardia cancer (Malekzadeh et al., 2009). However, the consumption of green tea is a preventive agent for stomach cancer (Ji et al., 1996).

Our study also showed that men are suffering more than women (from stomach cancer). Superiority of men to women at the risk of stomach cancer has been shown in other studies (Malekzadeh et al., 2009; Radmard, 2010; Hasanzadeh et al., 2013). This can be due to high incidence of risk factors in men. it has been shown that men smoke more than women (Malekzadeh et al., 2009; Radmard, 2010). Also, men are less likely to comply with sanitation resulting in lower age of $\mathrm{H}$. pylori infection (Malekzadeh et al., 2009).

In this study, we tried using geographic information system to identify any variation in the distribution of the disease. Determining Hot Spots in this study is done by Getis-Ord Gi* (Spatial Statistics). Although high-risk areas in the study indicate the importance of the incidence of stomach cancer, but it should be noted that several factors may be involved. Perhaps the high incidence of risk factors in Hot Spots justifies the differences, but other factors such as incomplete data registration, the loss of a full report of cases and bad data classification can be among factors affecting differences in the incidence of the disease in country for this reason, when using national data to examine spatial conditions, you should pay attention to the noted tips.

Stomach cancer is now the second most deadly cancer in Iran. Due to the high incidence of stomach cancer in North and North West of the country giving priority to these provinces in order to provide prevention and treatment services can be effective in reducing the incidence of disease

\section{References}

Abdi-Rad A, Ghaderi-Sohi S, Nadimi-Barfroosh H, et al (2006). Trend in incidence of gastric adenocarcinoma by tumor location from 1969-2004: a study in one referral center in
Iran. Diagn pathol, 1, 1-7.

Almasi Z, Rafiemanesh H, Salehiniya H (2015). Epidemiology characteristics and trends of incidence and morphology of stomach cancer in iran. Asian Pac J Cancer Prev, 16, 2757.

Aragonés N, Pollán M, Gustavsson P (2002). Stomach cancer and occupation in Sweden: 1971-89. J Occup Env Med, 59, 329-37.

Babaei M, Mousavi S, Malek M, et al (2005). Cancer occurrence in Semnan Province, Iran: results of a population-based cancer registry. Asian Pac J Cancer Prev, 6, 159-64.

Bédard Y, Gosselin P, Rivest S, et al (2003). Integrating gis components with knowledge discovery technology for environmental health decision support. Int J Mech Sci, 70, 79-94.

Çetin B, Atalay C, Aslan S, et al (2005). Peritoneal Carcinoembryonic Antigen Level for Predicting Locoregional and Distant Spread of Gastric Cancer. Surg Today, 35, 919-24.

Cocco P, Palli D, Buiatti E, et al (1994). Occupational exposures as risk factors for gastric cancer in Italy. Cancer Causes Control, 5, 241-8.

Derakhshan M, Yazdanbod A, Sadjadi A, et al (2004). High incidence of adenocarcinoma arising from the right side of the gastric cardia in NW Iran. Gut, 53, 1262-6.

Dorji D, Dendup T, Malaty HM, et al (2014). Epidemiology of helicobacter pylori in Bhutan: The role of environment and geographic location. Helicobacter, 19, 69-73.

Enayatrad M, Salehiniya H (2014). Trends in gastric cancer incidence in Iran. J Mazandaran Univ Med Sci, 24, 8-16.

Eusebi LH, Zagari RM, Bazzoli F (2014). Epidemiology of helicobacter pylori infection. Helicobacter, 19, 1-5.

Forman D, Burley VJ (2006). Gastric cancer: global pattern of the disease and an overview of environmental risk factors. Best Pract Res Clga J, 20, 633-49.

Ghadimi R, Taheri H, Suzuki S, et al (2007). Host and environmental factors for gastric cancer in Babol, the Caspian Sea Coast, Iran. Eur J Cancer Care 16, 192-5.

González CA, Jakszyn P, Pera G, et al (2006). Meat intake and risk of stomach and esophageal adenocarcinoma within the European Prospective Investigation Into cancer and nutrition (EPIC). J Natl Cancer Inst Monogr, 98, 345-54.

Hartgrink HH, Jansen EP, van Grieken NC, et al (2009). Gastric cancer. Lancet, 374, 477-90.

Hasanzadeh J, Hosseini Nezhad Z, Vardanjani M-e, et al (2013). Gender differences in esophagus, stomach, colon and rectum cancers in Fars, Iran, during 2009-2010: An epidemiological population based study. J Rafsanjan Univ Med Sci, 12, 333-42.

Ji BT, Chow WH, Yang G, et al (1996). The influence of cigarette smoking, alcohol, and green tea consumption on the risk of carcinoma of the cardia and distal stomach in Shanghai, China. Cancer, 77, 2449-57.

Kang SK, Burnett CA, Freund E, et al (1997). Gastrointestinal cancer mortality of workers in occupations with high asbestos exposures. Am J Indus Med, 31, 713-8.

Keyghobadi N, Rafiemanesh H, Mohammadian -Hafshejani A, et al (2014). Epidemiology and trend of cancers in the province of kerman: southeast of iran. Asian Pac J Cancer Prev, 16, 1409-13.

Malekzadeh R, Derakhshan MH, Malekzadeh Z (2009). Gastric cancer in Iran: epidemiology and risk factors. Arch Iran Med, 12, 576-83.

Massarrat S, Saberi-Firoozi M, Soleimani A, et al (1995). Peptic ulcer disease, irritable bowel syndrome and constipation in two populations in Iran. Eur J Gastroenterol Hepatol, 


$$
\text { 7, 427-33. }
$$

Mentis A, Lehours P, Mégraud F (2015). Epidemiology and diagnosis of Helicobacter pylori infection. Helicobacter, 20, 1-7.

Mostafavi E, Haghdoost A, Khakifirouz S, et al (2013). Spatial analysis of Crimean Congo hemorrhagic fever in Iran. $\mathrm{Am}$ J Trop Med Hyg, 89, 1135-41.

Pakzad R, Mohammadian-Hafshejani A, Mohammadian M, et al (2014). Incidence and mortality of bladder cancer and their relationship with development in Asia. Asian Pac J Cancer Prev, 16, 7365-74.

Pakzad R, Soltani S, Salehiniya H (2015). Epidemiology and trend in skin cancer mortality in Iran. J Res Med Sci, 20, 921-2

Parkin D, Whelan S, Ferlay J, et al (2002). Cancer incidence in five continents Vol. VIII. IARC scientific publications, 155.

Poulstrup A, Hansen H (2004). Use of GIS and exposure modeling as tools in a study of cancer incidence in a population exposed to airborne dioxin. Environ Health Perspect, 112, 1032-6.

Pourfarzi F, Whelan A, Kaldor J, et al (2009). The role of diet and other environmental factors in the causation of gastric cancer in Iran-A population based study. Int J Cancer, 125, 1953-60.

Radmard AR (2010). Five common cancers in Iran. Arch Iran Med, 13, 143-6.

Rahimi F, Heidari M (2012). Time trend analysis of stomach cancer incidence in the west of Iran. J Health Dev, 1, 100-11.

Rontoyannis GP, Stalikas A, Sarros G, et al (1998). Medical, morphological and functional aspects of Greek football referees. J Sports Med Phys Fitness, 38, 208-14.

Sadjadi A, Malekzadeh R, Derakhshan MH, et al (2003). Cancer occurrence in Ardabil: Results of a population-based Cancer Registry from Iran. Int J Cancer, 107, 113-8.

Sadjadi A, Zahedi M, Nouraie M, et al (2007). The first population-based cancer survey in Kerman Province of Iran. Iran J Public Health, 36, 26-34.

Sankaranarayanan R, Ramadas K, Qiao Y-1 (2014). Managing the changing burden of cancer in Asia. BMC Med, 12, 3 .

Sayehmiri F, Darvishi Z, Sayehmiri K, et al (2014). A systematic review and Meta-analysis study to investigate the prevalence of helicobacter pylori and the sensitivity of its diagnostic methods in Iran. Iran Red Crescent Med J, 16, e12581.

Siegel R, Ma J, Zou Z, et al (2014). Cancer statistics, 2014. CA Cancer J Clin, 64, 9-29.

Simpson J, Roman E, Law G, et al (1999). Women's occupation and cancer: Preliminary analysis of cancer registrations in England and Wales, 1971-1990. Am J Indus Med, 36, 172-85.

Swanson GM, Burns PB (1995). Cancer incidence among women in the workplace: a study of the association between occupation and industry and 11 cancer sites. J Occup Env Med, 37, 282-7.

Yomralioglu T, Colak EH, Aydinoglu AC (2009). Geo-relationship between cancer cases and the environment by GIS: A case study of Trabzon in Turkey. Int J Environ Res Public Health, 6, 3190-204. 